\title{
Relationship Between Mastery Goal Orientation and Achievement in Mathematics of Indian School Students Using Karl Pearson's Parametric Correlation
}

\author{
Babu M. Sameer*, S. Selvamari \\ Department of Education, University of Kerala, Thiruvananthapuram, India \\ Email address: \\ Sameer@keralauniversity.ac.in (B. M. Sameer) \\ ${ }^{*}$ Corresponding author
}

To cite this article:

Babu M. Sameer, S. Selvamari. Relationship Between Mastery Goal Orientation and Achievement in Mathematics of Indian School Students Using Karl Pearson's Parametric Correlation. International Journal of Secondary Education. Vol. 7, No. 1, 2019, pp. 1-5. doi: $10.11648 /$ j.ijsedu.20190701.11

Received: January 5, 2019; Accepted: February 12, 2019; Published: February 25, 2019

\begin{abstract}
The prime aim of this paper is to identify the degree of relationship between Mastery Goal Orientation, and Achievement in Mathematics of Indian School Students. The study was designed in correlational design. Sampling procedure was multistage cluster technique. 204 ninth graders were selectedas sample of the study. Mastery Goal Orientation scale was used to collect data; and Achievement score in mathematics was taken from the school records, which was mathematically treated to obtain standard score. The study shows that there is a positive significant relationship between Mastery Goal Orientation, and Achievement in Mathematics. Results show that an increase level of Mastery Goal Orientation will lead to increase in the level of Achievement in Mathematics. The adolescents must learn to do things by themselves- fixing target, working on the same, analyzing the impact, etc. A working model for adolescent can be suggested which can be an effective mechanism to help them set goals and related task orientation. Teachers can also design such strategies employing their own apt strategies. Goals can be asked and detailed out in the classroom, and at home along with the required efforts and hard work.
\end{abstract}

Keywords: Mastery Goal Orientation, Achievement in Mathematics, Secondary School Students, Performance Orientation, Classroom Learning

\section{Introduction}

It is common that people vary in their motives and orientations for engaging in specific achievement behaviours and endorse various achievement goal orientations [8-10, 26]. Obviously, Achievement backgrounds varying with respect to the achievement goal orientations of the individual since all of us (human beings) have diverse orientations and inclinations. In a school setting, learners' goal orientations play a vital role in their academic achievement contexts [8, 13]. Over the past three decades, educational psychology researches focus on the student's goal orientations in one way or the other.

Goal orientation theory was proposed by Nicholls, who believed that students take on task involvementor ego involvement [22]. Thus, from general point of view, the achievement goal theory has been technologically advanced from the work of numerous famous researchers who were the main contributors to the goal orientation theory such as Dweck [7], Nicholls [22], Ames [1], et al. They established new zone of research in the academic motivational spacehighlighting significance of goals in human life space [21].

Goal orientation refers to the pattern of cognition and action that results from pursuing achievement goals [4]. It has been associated with concepts such as meta-cognitive activity [30], intrinsic motivation [12], and learning strategies [31]. Achievement goal orientation has been described as the set of purposes or reasons students may adopt for performing an academic task [7, 28]. Therefore, Goal orientation is one of the concepts that has emerged in educational psychology and also is one of the most important concepts regarding learning in any educational setting [21].

Recently, many researchers have adopted a goal 
orientation framework and labeled different types of goals such as learning versus performance; mastery versus performance; and task mastery, ego social, and workavoidant. Among them the mastery and the performance goal orientations are dominant. Students with Mastery Goal Orientation try to acquire knowledge to learn and increase their competence for self-development. These students believe that effort is the cause of success or failure. Central for mastery goal-oriented individuals is the focus on learning, developing new skills, improving the level of proficiency and trying to understand new learning subjects. Students with a Mastery Goal Orientation show a motivational pattern which is likely to promote long-term and high-quality involvement in activities and learning: a Mastery Goal Orientation can certainly influence various levels of learning- the cognitive, motivational and behavioural aspects of adaptive aspects of learning.

Mastery goal orientation is associated with approachoriented activities including effort, persistence and task absorption [11]. Payne et al.'s meta-analysis [27] reported a positive relationship between dispositional mastery orientation and both learning (exam performance) and academic progress along with job prospects [13].

Manyresearchers concludedthat Mastery goals encourage outcome and human performance in a greater level [32], [15]. The fact is that mastery goal plays a pivotal role in hypothesizing the motivation of students and predicting students' academic progress and related achievement. There are plenty of studies carried out in this line-i.e. achievement goal orientation. Little research has been reported in Indian research literature, particularly from south India. And hence, to investigate the relationship between mastery goal orientation and achievement in mathematics of secondary school students is a significant attempt. In this present study, the following concerns will be addressed.

1. Do the secondary school students have a fixed orientation towards their goals? And is it to the level of mastery?

2. Is there any relationship between Mastery Goal Orientation and achievement in Mathematics? To what extent if exists?

\section{The Study}

The aim of the current study is to examine the relationships between mastery goal orientation and achievement in mathematics. The study focuses on students' mastery goals in relation to achievement in Mathematics. Here, the authorsdelimited the study to academic domain because evidence suggests that children's motivation-related beliefs and perceptions tend to be differentiated according to achievement domains quite early $[14,18]$ and that domain- specific measures of motivation tend to be more prognostic of learning indices than general measures [3], [19]. In the present study three hypotheses were formulated. First one is secondary school students have an average level of Mastery Goal Orientation, and second hypothesis of the current study is Secondary school students have an average level of Achievement in Mathematics. Furthermore, there is a significant relationship between Mastery Goal Orientation and Achievement in Mathematics of secondary school students of India.

\section{Methodology}

\subsection{Participants}

204 Ninth graders, from selected secondary schools of South India- Thiruvananthapuram district of Kerala, were selected using multi stage cluster sampling. Among them, 84 boys $(58.82 \%)$ and 120 girls (41.18\%). Ages rangedfrom 13 years to 15 years.

\subsection{Measures}

Mastery Goal Orientation scale, Data profile are used measures for the present study. Additionally, achievement score in mathematics were taken from the school record which is assigned by the mathematics teacher.

\subsubsection{Mastery Goal Orientation}

The authors developed a mastery goal orientation scale. Firstly, a pilot study was conducted among 130 secondary school students. The draft scale consists of 60 statements. After validation of the tool, the final scale has of 34 statements. The reliability of the scale was obtained Cronbach's Alpha coefficient $=0.76$, split half spearman brown $=0.80$, and split half Guttman $=0.80$. Content validity was confirmed by psychology and Educational Psychology experts from India and abroad (13 experts commented on the scale). Cross validity, and concurrent validity(correlating with the scores obtained administering the scale of Duda\& Nicholls [6], [24]) also established;they are 0.31 and 0.57 correspondingly. The Mastery Goal Orientation scale was fit in to the 5 point Likert scale end description with end points as strongly Agree (5 score) and Strongly Disagree (1 score) for positive statements, which is assigned reverse for the negative statements. The possible scores ranges from 34 to 170 .

\subsubsection{Achievement in Mathematics}

For measuring achievement in mathematics, achievement scores were taken from the school records, which weresupplied by the respective mathematics teachers. The score was converted in to the standard score(z- score) before analysis.

\section{Results}

Table 1. The descriptive statistical scores such as Mean, standard error of mean, standard deviation, variance, skewness, and kurtosis.

\begin{tabular}{|c|c|c|c|c|c|c|c|}
\hline Variable & $\mathbf{N}$ & Mean & Std. Error of Mean & Std. Deviation & Variance & Skewness & Kurtosis \\
\hline Mastery Goal Orientation & 204 & 120.6373 & 1.05757 & 15.10508 & 228.163 & 0.493 & 0.172 \\
\hline
\end{tabular}


It is evident from the table 1, mean and standard deviation of Mastery Goal Orientation of secondary school students are 120.64 and 15.11 respectively. It is interpreted that they have moderate level of Mastery Goal Orientation as per the qualitative norms of the scale.

Table 2. The number and percentage of students in different Mastery Goal Orientation levels.

\begin{tabular}{llll}
\hline Sl. No. & Level of Mastery Goal Orientation & Number & Percent (\%) \\
\hline 1 & Highly Mastery Goal Orientation & 21 & 10.29 \\
2 & Moderately Mastery Goal Orientation & 130 & 63.73 \\
3 & Feebly Goal Orientation & 53 & 25.98 \\
& Total & 204 & $100 \%$ \\
\hline
\end{tabular}

It is inferred that most of the students are having moderate Mastery Goal Orientation (63.73\%). It is also clear that $25.98 \%$ of them are in the feebly goal oriented category. A histogram of the scores is given below.

Second objective of the present was to find out the level of Achievement in Mathematics of secondary school students.

Table 3. Descriptive statistical scores of Achievement in Mathematics.

\begin{tabular}{|c|c|c|c|c|c|c|c|}
\hline Variables & $\mathbf{N}$ & Mean & Std. Error of Mean & Std. Deviation & Variance & Skewness & Kurtosis \\
\hline Achievement in Mathematics & 206 & 49.9322 & 0.69666 & 9.99895 & 99.979 & -0.23 & -0.999 \\
\hline
\end{tabular}

It is evident from the table, the mean and standard deviation of Achievement in Mathematics of secondary school students are 49.93 and 9.99 respectively. They are in average level of achievement as per the norms formulated.

Table 4. The number and percentage of students in different levels of Achievement in Mathematics.

\begin{tabular}{llll}
\hline Sl. No. & Level of Achievement & Number & Percent (\%) \\
\hline 1 & High & 105 & 51.47 \\
2 & Average & 44 & 21.57 \\
3 & Low & 55 & 26.96 \\
& Total & 204 & $100 \%$ \\
\hline
\end{tabular}

From table 4, most of the students fall in $26.96 \%$ level of Achievement in Mathematics. At the same time $51.47 \%$ of them fall in high achievement level.

Third objective of the study was to find out the relation between Mastery Goal Orientation, and Achievement in Mathematics of secondary school students.

Table 5. Relationship between Mastery Goal Orientation and Achievement in Mathematics.

\begin{tabular}{ll}
\hline Variables & Achievement in Mathematics \\
\hline Mastery Goal Orientation & $.196^{* *}$ \\
\hline
\end{tabular}

**. Correlation is significant at 0.01 level (2-tailed).

The product moment correlation coefficient between Mastery Goal Orientation and Achievement in Mathematics $(\mathrm{r}=0.196)$ is negligible and positive correlation; but it is significant at 0.01 level. Thus it is interpreted there is a significant positive correlation between the variablesMastery Goal Orientation and Achievement in Mathematics. It means that an increase in Mastery Goal Orientation leads to a corresponding increase in Achievement in Mathematics.

\section{Discussion of the Result}

The present study revealed that secondary students have a moderate level of Mastery Goal Orientation, and secondary school students have high level of Achievement in Mathematics. For the mastery goals, students believe that if the learners try harder, the ability can be developed [7], [34].
The relationship between goal orientation and academic achievement is well established in the literature. Mastery goal is counted as the greater achievement provider [20]. Studies found Mastery-approach goal orientation statistically significantly correlated with Achievement in Mathematics [33]. Therefore, the results of the present study strongly support the existing literature, i. e., a positive relationship between Mastery Goal Orientation and Achievement in Mathematics.

In the educational psychology research, motivation is regarded as an internal part that students lead to task along with the goals they held which leads to their success and failure [17]. In fact, what is of great importance for the accomplishment of students is the origin of students' motivation and engagement in learning and academic activities [21]. Teachers should have knowledge of the same and they have to ensure the level of goal orientation among their students. Central for mastery goaloriented is the individuals is the focus on learning, developing new skills, improving the level of competence and trying to understand new learning subjects are characteristics of the mastery goal oriented students. Teachers should allow students to think independently and appreciate their responses; need to give feedback of their achievement. And curriculum should framed for cognitive development way.

The results obtained from the present study are helpful in giving recommendations and suggestion to the policy makers and school related authorities. Certain recommendations and suggestions are proposed to foster Achievement in Mathematics among Secondary School Students.

Goals can be asked and detailed out in the classroom and at 
home along with the required efforts and hard work.

Teachers should try to maintain a good relationship with adolescent learners.

The growing need for independence and privacy of adolescents are to be recognized by the teachers and parents in a positive way.

Teachers should provide regular information relating to the developmental characteristics of adolescents (social workers, dieticians, and pediatricians can be given role).

\section{Mastery Goal Orientation}

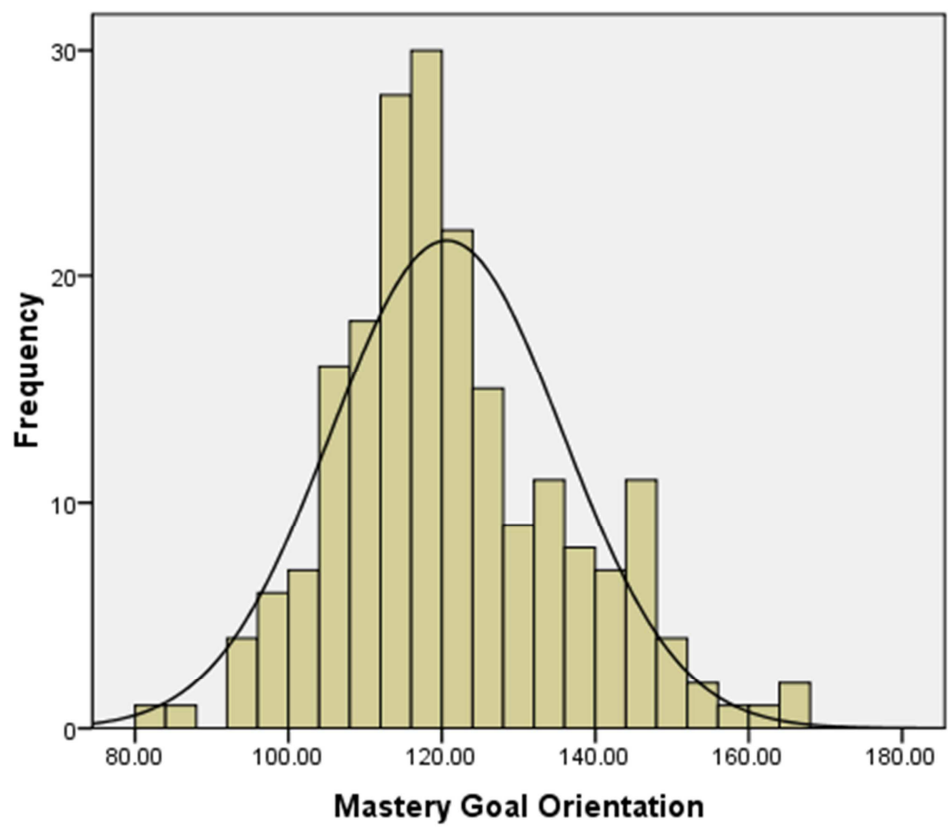

$\begin{aligned} \text { Mean } & =120.64 \\ \text { Std. Dev. } & =15.105\end{aligned}$ $\mathrm{N}=204$

Figure 1. Histogram of the distribution-Mastery Goal Orientation.

\section{Conclusion}

The study shows a positive relationship between mastery goal orientation and achievement in Mathematics. It is thus concluded that goals of the learning and suggested outcomes should be clarified to students so that they will be able to set standards by following the instructions of the teachers. Similarly, they will be developing a sense of responsibility in learning which would be helping them in devising learning strategies with the help of the facilitators.

A working model for adolescent can be suggested which will be an effective mechanism. Teachers can design it employing their own apt strategies. The adolescents must learn to do things by themselves- fixing target, working on the same, analyzing the impact, etc. The framework is suggested as: Macro Planning- Goal Setting- Analyzing the Situation- Need Analysis- Listing of Strategies- Listing of Resources- List of Support System-- Listing of Specific Tips- Listing of Required Help and Support- Listing of Split of Time - Follow Up

\section{References}

[1] Ames, C. (1992). Classrooms: Goals, structures, and student motivation. Journal of Educational Psychology, 84 (3), 261-271.

[2] Andrew J. Martin, Herbert W. Marsh, Raymond L. Debus, \&LarsErik Malmberg (2008). Performance and Mastery Orientation of
High School and University/College Students, hosted at 2008 Sage Publications, available online at http: //epm.sagepub.com. doi: $10.1177 / 0013164407308478$.

[3] Assor, A., \& Connell, J. (1992). The validity of students' selfreports as measures of performance affecting self-appraisals. In D. Schunk \& J. Meece (Eds.), Student perceptions in the classroom (pp. 25-50). Hillsdale, NJ: Erlbaum.

[4] DeShon, R. P., \& Gillespie, J. Z. (2005). A motivated action theory account of goal orientation. The Journal of Applied Psychology, 90 (6), 1096-1127. doi: 10.1037/00219010.90.6.1096.

[5] Duda, J. L. (1992). Motivation in sport settings: A goal perspective approach. In G. C. Roberts (Ed.), Motivation in sport and exercise (pp. 57-91). Champaign, IL: Human Kinetics Books.

[6] Duda, J. L., \& Nicholls, J. G. (1992). Dimensions of achievement motivation in schoolwork and sport. Journal of Educational Psychology, 84, 290-299.

[7] Dweck, C. S. (1986). Motivational processes affecting learning. The American Psychologist, 41 (10), 1040-1048. doi: 10.1037/0003066X.41.10.1040.

[8] Dweck, C. S., \& Leggett, E. L. (1988). A social-cognitive approach to motivation and personality. Psychological Review, 95(2), 256-273. doi:10.1037/0033-295X.95.2.256.

[9] Elliot, A. J. (2005). A conceptual history of the achievement goal construct. In A. J. Elliot \& C. S. Dweck (Eds.), Handbook of competence and motivation (pp. 52-72). New York, NY: Guilford Press. 
[10] Elliot, A. J., \& McGregor, H. A. (2001). A $2 \times 2$ achievement goal framework. Journal of Personality and Social Psychology, 80 (3), 501-519.

[11] Elliot, A., Shell, M., Bouas Henry, K., \& Maier, M. (2005). Achievement goals, performance contingencies, and performance attainment: An experimental test. Journal of Educational Psychology, 97 (4), 630-640. doi: 10.1037/0022-0663.97.4.630.

[12] Elliot, A., \& Church, M. A. (1997). Ahierarchical model of approach and avoidance achievement motivation. Journal of Personality and Social Psychology, 72, 218-232. doi: 10.1037/0022-3514.72.1.218.

[13] Yeo, sorbello Tamara, \& koy Annette (2008). Task performance growth trajectories. Springer Science+ Bussiness, media, LLC2008, published online 5 Auguest.

[14] Gottfried, A. E. (1990). Academic intrinsic motivation in young elementary school children. Journal of Educational Psychology, $82,525-538$.

[15] Hulleman, C. S., Schrager, S. M., Bodmann, S. M., \& Harackiewicz, J. M. (2010). A meta-analytic review of achievement goal measures: Different labels for the same constructs or different constructs with similar labels? Psychological Bulletin, 136, 422-449. doi: 10.1037/a0018947.

[16] Lavinia E. Damian, Joachim Stoeber, OanaNegru, \& Adriana Baban (2012). Perfectionism and achievement goal orientations in adolescent school students, Psychology in the Schools, Vol. 51 (9), 2014, Wiley Periodicals, Inc available online at wileyonlinelibrary.com/journal/pits doi: 10.1002 /pits. 21794 .

[17] Leondari, A., \&Gonida, E. (2007). Predicting academic selfhandicapping in different age groups: The role of personal achievement goals and social goals. British Journal of Educational Psychology, 77, 595-611. doi: 10.1348/000709906X128396.

[18] Marsh, H. W., Craven, R. G., \& Debus, R. (1991). Selfconcepts of young children 5 to 8 years of age: Measurement and multidimensional structure. Journal of Educational Psychology, 83, 377-392.

[19] Meece, J. L., \& Miller, S. D. (2001). A longitudinal analysis of elementary school students' achievement goals in literacy activities. Contemporary Educational Psychology, 26, 454480 .

[20] Midgley, C., Kaplan, A., \& Middleton, M. (2001). Performance-approach goals: Good for what, for whom, under what circumstances, and at what cost? Journal of Educational Psychology, 93, 77-86.

[21] Nasser Rashid, FatemaJavanmardi (2012). The Relationship between Iranian EFL Students' Achievement Goal Orientations and Their Gender, Education 2012, 2 (1): 8-15, Published online at http://journal.sapub.org/edu, doi: 10.5923/j.edu.20120201.02.

[22] Nicholls, J. G. (1975). Causal attributions and other achievement-related cognitions: Effects of task outcome, attainment value, and sex. Journal of Personality and Social Psychology, 31, 379-389.

[23] Nicholls, J. G. (1984). Achievement motivation: Conceptions of ability, subjective experience, task choice, and performance. Psychological Review, 91, 328-346.

[24] Nicholls, J. G. (1989). The competitive ethos and democratic education. Cambridge, MA: Harvard University Press.

[25] Nicholls, J., Cheung, P., Lauer, J., \&Patashnick, M. (1989). Individual differences in academic motivation: Perceived ability, goals, beliefs and values. Learning and Individual Differences, 1 (1), 63-84. doi:10.1016/1041-6080 (89) 900101.

[26] O'Keefe, Paul A., Adar Ben- Eliyahu, \&Lisa LinnenbrinGarcia (2012). Shaping achievement goal orientations in a mastery-structured environment and concomitant changes in related contingencies of self-worth. Springer Science+Business Media, MotivEmot (2013) 37: 50 64 5, LLC 2012. doi: 10.1007/s11031-012-9293-6.

[27] Payne, S. C., Youngcourt, S. S., \&Beaubien, J. M. (2007). A meta-analytic examination of the goal orientation nomological net. Journal of Applied Psychology, 92, 128-150.

[28] Pintrich, P. R. (2000a). Multiple goals, multiple pathways: The role of goal orientation in learning and achievement. Journal of Educational Psychology, 92 (3), 544-555. doi: 10.1037/0022-0663.92. 3.544

[29] Pintrich, P. R. (2000b). The role of goal orientation in selfregulated learning. In M. Boekaerts, P. R. Pintrich\& M. Zieder (Eds.), Handbook of self-regulation. San Diego: Academic Press.

[30] Schmidt, A. M., \& Ford, J. K. (2003). Learning within a learner control training environment: The interactive effects of goal orientation and metacognitive instruction on learning outcomes. Personnel Psychology, 56, 405-429. doi: 10.1111/j.1744-6570. 2003. tb00156.x.

[31] Zusho, A., Pintrich, P. R., \& Coppola, B. (2003). Skill and will: The role of motivation and cognition in the learning of college chemistry. International Journal of Science Education, 25 (9), 1081-1094. doi: 10.1080/0950069032000052207.

[32] Baranik, L. E., Roling, E. A.,\&Eby, L. B. (2010). Why does mentoring work? The role of perceived organizational support. Journal of VoccationalBehaviour, 76 (3), 366-373.

[33] Keys, T. D., Conley, A. M., Duncan, G. J.,\&Domina, T.(2012). The role of goal orientation for adolescent mathematics achievement. Contemporary Educational Psychology 37 (1), 47-54.

[34] Korkmaz, U. (2014). Achievement goal orientation and its relation to academic achievement. Journal of Education and Humanities: Theory and Practice, 5 (10), 137-147. 